Planing is very common, and is either flit or with a hollow or a convex surface. Some of the intensely hard hornfels blocks have been ground on one or more sides, several planes being sometimes ground on the same stone, while some very hard rocks are deeply grooved. In other cases the striations and scratches are so fine as only to be seen with a lens; while one surface block of very hard material has been ground down and polished, so that it glitters in the sun. In fact, every form of surface-grinding produced by recent glaciation appears to be here present.

The surface of the ground is everywhere strewn with pebbles and boulders, the result of the washing away of the finer materials of the conglomerate; but, besides these, there is a tract of about two and a half miles by one mile near the centre of the conglomerate-area, on the north side of Mount Ida Creek, which is rather thickly strewn with large blocks, termed by the writer " erratics," though they can hardly be erratics in the sense of having been deposited on the present surface by ice. There are forty-five of these blocks, which are either of granite, sandstone, or quartz, and vary in size from 6 feet by 4 feet, to 20 by 12 feet. One of the finest, termed "The Stranger," of coarse-grained granite, is I $6 \frac{1}{2}$ feet by - $10 \%$ feet, and 5 feet thick, the estimated weight being 30 tons. It is planed and scored in a remarkable manner, is are most of the other blocks. It is curious that beyond this limited area only three or four large blocks are found on the surface, while no pebbles or boulders derived from the conglomerate are found more than a hundred yards beyon I the present limits of that formation.

A striking feature of the conglomerate is the great variety of rocks present in it, seeming as if "the débris of a continent " had been here gathered together. There are an almost infinite variety of granites, syenites, gneisses, schists, quartzites, sandstones (hard and soft, coarse and fine), slates, shales, conglomerates, amygdaloids, porphyries, vein-quartz, red, yellow, and grey jaspers, and many others. Some of these can be identified with existing rocks, but others are not known in Victoria. In some cases there is what appears to be river shingle, in others the delicate scratches preserved even on soft shale show that the material has not been exposed to any denuding action. There are also sandstone beds of considerable extent and thickness intercalated with the conglomerate, indicating that there were alternating periods of river or current action while the conglomerate was being formed.

The whole of the phenomena here briefly sketched point unmistakably to glacial action ; in fact, there seems to be hardly any part of Wales or Scotland where such action is more clearly indicated. There are, it is true, no moraines, because the period when the conglornerate was laid down is too remote, both newer and older pliocene rocks overlying it in some places. Indeed, from fossils found in shales overlying what appears to be a similar conglomerate at Bacchus Marsh, south of the Dividing Range, the writer of the report is inclined to consider the whole formation to be of Palæozoic age. In one part of the area the bed rock is exposed, and this is covered with abundant striations crossing the stratification lines, indicating either powerful glacier or iceberg action.

A list of localities where similar conglomerates have been found is given, showing that they occur to the northward for about 250 miles along the foot of the hills bordering the Murray valley, disappearing under the Tertiary deposits of the lowlands; they have also been niet with forming the floor of the auriferous deposits in mines at Creswick and Carisbrook, on the northern slopes of the Dividing Range ; and also, as already stated, at Bacchus Marsh, and a few other localities on the south side of the range. We are not told, however, whether similar indications of glacial action occur in these localities. If these deposits are really all glacial and

No. I $20_{3}$, VOL, 47] contemporaneous, they indicate an extent of glaciated country that would imply either a very lofty mountain range or the occurrence of a real glacial epoch in the southern hemisphere.

The direct evidence of the superposition of Tertiary rocks of Pliocene age shows that the glacial conglomerate itself is of great antiquity, but no special attention appears to have been given to the question of the age of the so-called "erratics." The fact that they are found in so limited an area seems to show that they are not derived from the conglomerate itself by the process of sub-aerial denudation, and the same thing is indicated by the apparent fact that they all rest upon the present land surface. The photographs seem to indicate this, and nothing is said about their relations to the subjacent conglomerate, or whether any considerable proportion of them still form part of it, merely protruding above the surface, as would certainly be the case if they owe their present position to the mere washing away of the finer parts of the deposit. But, if so, why should they be called "erratics," as distinguished from the blocks and boulders which are still embedded in the formation? If, on the other hand, they are supposed to be trua erratics-that is, to have been deposited on the present land-surface by ice agency-they must clearly be much less ancient than the conglomerate itself, or they would hardly retain such fresh-looking striations, grooving, and polishing as some of them exhibit. It is to be hoped that these most interesting deposits will be the subject of very careful study by Australian geologists, since they seem calculated to throw much light on the geological history of the old Australian continent.

AlFred R. Wallace.

\section{ON THE WALKING OF ARTHROPODA.}

I $\mathrm{N}$ a letter to NATURE, published January 8, I891, I described the manner of walking of several insects. Recently I have been able to examine a greater number of Hexapoda, together with several Arachnida and Centipedes, and a few Crustacea. The results of most of these observations were communicated to the Royal Dublin Society a few weeks ago.

I stated in my former letter that most usually the insects examined moved three legs, e.g. the Ist and 3 rd on one side, and the and on the other, almost, but not quite, simultaneously. In some insects it is the most anterior leg of this tripod which is raised first; in others it is the most posterior. An example of the first case is the cockroach, and of the second the blow-fly. But again exceptions appear to occur in each case. This almost simultaneous raising of the "diagonals" is shown by observations, photographic and otherwise, to be the rule in all the adult Hexapoda which I have examined, except the Thysanura. Of this last group I have observed Tomocerus longicornus, and find that, while it often moves by the simultaneous use of the diagonals, it also often raises its opposite legs simultaneously in pairs, especially when the animal is walking on a smooth surface, and using the sucker which is placed on the anterior part of the abdomen.

This use of the opposite legs in pairs was also found very frequently, as well as the diagonal walk, in the larva of one of the Coleoptera, and is always to be observed in caterpillars. Thus it is interesting to find that in one species at least of the Thysanura, which are regarded as having preserved many of the characteristıcs of primitive insects the adult walks in the same manner as the larva of other insects.

It is to be observed that those insects which have long antennæ move them, and apparently the maxillary palps, in accordance with the diagonal rule; for when the front leg of one side is moved the antenna of that side is twitched. 
A midge and some arachnids very frequently use the front pair of walking legs as antennæ. The midge which I observed probably belonged to the Cheironomidæ ; it often, when at rest, stood on the two posterior pairs of legs with the anterior pair aloft in the air ; when walking it moved them much as a beetle moves its antennæ, gently tapping the ground in front of it with them, their motions being always subject to the diagonal rule; in flight the midges often hold the anterior pair of legs straight out in front, while the last pair are held out in a similar manner behind, and probably have the effect of balancing the insect.

The spiders photographed (Tegenaria Derhamii and Tarantula pulverulenta) also exhibited the diagonal motion and sometimes the use of the anterior pair of legs as antennæ. When, in order to photograph them, these animals were put on a piece of paper floating in a shallow dish of water, so as to confine them without casting a shadow on the space in which they walked, they used frequently to stand on the three posterior pairs of legs at the edge of the paper, while they moved their anterior pair of legs through the air, or touched the water lightly with them. Several spiders-for instance, Theridion Sisyphum-have the anterior pair of legs longer than the others, and very frequently seem to use them as tactile organs. Specialization in this direction is carried very far in the Pedipalpi, in which group the anterior pair of legs are very long, thin, and flagelliform.

The wave of motion in one set of diagonals (i.e. the Ist and 3 rd of one side, and the 2 nd and 4 th of the other) in the Tarantula sometimes travelled from before backwards and sometimes in the opposite direction; while in Tegenaria it passed on the whole forwards, but sometimes commenced by the raising of one of the middle legs, or by the raising of the two extreme legs of a set.

When confined on the floating island of paper, the Tarantula sometimes, after a good deal of hesitation, took to the water. When on the surface of the water, its legs, and sometimes the under surface of its abdomen, made conical capillary depressions in the surface, so that the water acted as a diffusing lens to the sunlight, and a dark circular shadow surrounded with a bright line appeared on the bottom of the dish corresponding to the depression at the tip of each leg. This suggested a method of determining the weight supported by each leg, for the diameter of the depressions, and consequently that of the shadows, bears some ratio to the weight on the point which causes the depressions. By fixing the leg of a spider on the end of a straw, hung delicately as a balance-beam, and by measuring the diameters of the shadows caused by the depressions in the surface of the water formed by this leg for various positions of a rider on the straw, I find that these diameters are approximately proportional to the weight on the point causing the depressions. Thus, by dividing the total weight of the spider proportionally to the diameters of the shadows, we get approximately the weight on each leg.

Fig. I is from a photograph of the Tarantula standing

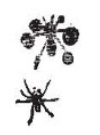

Flic. r.

on water; above the spider in the picture is its shadow on the bottom of the vessel, and at the ends of the three posterior pairs of legs in the shadow appear circular shadows corresponding to the depressions made by the legs; and there is also a shadow thrown by the depression caused by the abdomen. The weight of this spider was 30 mgrs. Thus we find that approximately the weights on the legs are the following:--On the right side, 2nd supports I. 875 mgrs.; 3rd, 7.125 mgrs.; 4th, 3.375. ( $n$ the left side, 2 nd, 4875 mgrs. ; 3 rd, 5.250 ; 4 th, 3.000 ; and the abdomen supports 4500 mgrs. When walking, the Tarantula usually supported all its weight on a tripod formed by the and and 4th legs on one side, together with the 3 rd leg on the other side. The weights on the tips of the legs when one photograph was taken were found to be :- On the 2nd right leg, 950 mgrs.; on the 4 th right, I0.25; and on the 3 rd left, 10.25.

Profile photographs also seem to show that the Ist pair of legs are not generally used to support much weight. Fig. 2 is a diagram of the positions of the Ist pair of legs

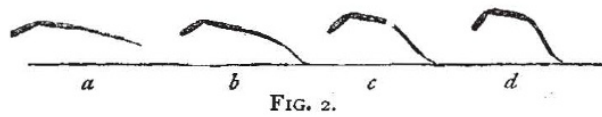

drawn from a number of profile photographs of Tegenaria. The first position, $a$, is that of the leg which has been thrown forward, and is just about to come to the ground ; $d$ shows the position of the ist leg when the body has come forward, owing probably to the traction of this leg as well as to the pushing of some of the other legs, and so the leg is bent; $b$ and $c$ are intermediate positions. The next

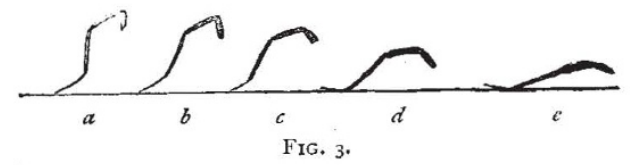

figure is a somewhat similar diagram of the 4th pair of legs made from profile photographs. At $a$ the leg has just been moved forward, and is on the ground, and is in a good position both for bearing the weight of the boty and shoving it forward. At $e$ it is stretched to its full length, and so is not of any use in driving the spider forwards, while, owing to its almost horizontal position, it is almost useless in supporting the weight of the body. Accordingly the spider has commenced to raise the extremity of the leg prior to lifting the leg completely off the ground.

Last autumn I had the opportunity of observing two scorpions which Mr. R. J. Moss brought from North Africa and exhibited at the Royal Dublin Society. These also appear to proceed according to the diagonal rule; but I do not know what is the order of succession in one set of diagonals, as I have not yet photographed any of these animals.

The hermit crab uses three pairs of legs in walking the chelce, and two pairs of thoracic walking legs; these it uses according to the diagonal rule, whether it walks sideways or forwards. Sometimes it simply shoves the chelæ along the ground without lifting them, while it moves the two pairs of legs in a diagonal manner. One of the Asellidae I found often used the opposite legs in pairs simultaneously when walking.

The centipede does not either raise its opposite legs in pairs together, nor does it move its legs according to the diagonal rule. In a number of photographs taken with an exposure of about the $\frac{7}{70}$ th of a second the legs appear to move in threes diagonally, for instance, the $3 \mathrm{rd}, 4$ th, and 5 th, and the 9 th, Ioth, and IIth on one side move simultaneously with the $6 \mathrm{th}, 7 \mathrm{th}$, and 8 th of the other side, while on the first side mentioned the $6 \mathrm{th}, 7 \mathrm{th}$, and $8 \mathrm{ch}$, with the 12th, 13th', and 14th are on the ground, and on the other side the 3 rd, $4^{\text {th }}$, and 5 th, and 9 th, Ioth, and IIth are also on the ground. At either end of the body this order is usually more or less disturbed; thus on the right side the I th leg might be on the ground, while on the left the I3th, I4th, and I 5 th would be also in contact with the ground; but

$$
\text { NO. } 1203 \text {, VOL. } 477
$$


in none of the photographs was the symmetrical diagonal movement of the successive threes disturbed between the 2nd and i2th pairs of legs inclusive. This apparently simultaneous motion of three adjoining legs may probably be explained by supposing a series of waves, whose crests traverse three legs in the $\frac{1}{70}$ th of a second, to be passing along the body, since the different photographs show different legs moving in threes; thus in one photograph the $6 \mathrm{th}, 7 \mathrm{th}$, and 8 th on the left sideare seen to be moving forward, while in another the 5 th, $6 \mathrm{th}$, and $7 \mathrm{th}$, are moving.

Since reading the paper at the Royal Dublin Society, Mr. G. H. Carpenter brought to my notice two papers by M. Jean Demoor, "Recherches sur la Marche des Insectes et des Arachnides" (Archives de Biologie, 189o) and "Recherches sur la Marche des Crustacés" (Archives de Zoologie Expérimentale et Générale, I891). M. Demoor points out the simultaneous use of the tripod in the insects which he examined, but as he did not use photography he does not seem to have observed the minute want of synchronism of the legs of a tripod. Figs. 4 and 5 illustrate this. ${ }^{1}$ These are two photographs taken of the same specimen of Blaps mucronata. Fig. 4 is from a photo-

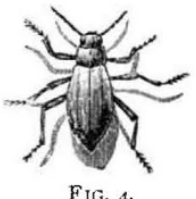

graph taken with a long exposure, and shows the Ist and 3 rd of the left side, and the 2 nd of the right moving at the same time, just as it appears to the eye. Fig. 5 is from

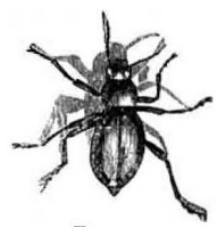

FIG. 5.

a photograph taken with less than half the exposure of 4 , and shows that while the Ist leg on the right side is raised off the ground, the 3 rd on the same side and the and on the left have not yet been raised. That they have not been raised and are now come to rest is shown by their backward position with regard to the body and other legs. These two photographs also show that the antenna is often twitched almost simultaneously with the motion of the Ist leg of its side. M. Demoor also observed a scorpion (Buthus australis), but its method of progression does not seem to have agreed with that of the scorpions (Buthus europaus) which I observed. $\mathrm{He}$ has not, so far as I know, recorded any observations on spiders.

Trinity College, Dublin, June. HENRY H. DIXON.

\section{ON IRON ALLOYS.}

THE merely mechanical expert in the working of metals would naturally consider it probable that a given metal when fused with another would communicate its physical properties, roughly, in proportion to the quantity added. A soft, tough metal added to iron would, from his point of view, render the latter softer; a brittle or hard metal would have the contrary effect, and so on throughout the whole series of metallic alloys.

I Figs. 4 and 5 show the legs, which are raised from the ground, quite sharp. In the negative they are more or less blurred owing to their motion during the exposure.

No. I 203, vOL. 47j
Actual experiment would soon, however, show the fallacy of this, and that in the majority of cases no reliance could be placed on this assumption solely based on the physical properties of the elements severally considered. A further study of the laws which govern chemical combination would quickly show that alloys formed by fusion were not merely intermixtures, but that something else took place, bodies being often produced, or rather formed, differing considerably from the metals severally used. It would therefore be fair to assume that the metals entered into combination with each other, and yet it would be found that the problem even at this stage was not completely solved.

Further inquiry and experiment would indicate that it was not always possible to prove that chemical combinations "were in all instances" formed by fusion alone. Instead of this something closely akin to only an intermixture of the metals occurred; second, one of the metals had apparently dissolved in the other; third, it was difficult to differentiate betwixt intermixture and solution. Here we are on all fours with modern ideas which seem to have met with general acceptance, although it is not denied that elements or metals are capable of chemically combining with each other. We are not, however, quite prepared to draw a hard and fast line betwixt chemical combination of the metals with each other, solutions, and intermixtures of metals. One appears to merge into the other, and no good reason "so far as is known" can be given why solution, as ordinarily understood, or as defined by Van 't Hoff and others, may not be as applicable to fused metals as to the solution of certain salts in water.

Water at $60^{\circ}$ is nothing more nor less than fused ice; fused iron, therefore, may obey the same laws, and, "like water," may be capable of dissolving certain substances, and rejecting others, temperature constituting the sole difference-or plainly, solid ice is fusible at $60^{\circ}$, iron at about $2500^{\circ}$.

Now what happens in the case of water? Certain bodies are soluble in it, others not ; on lowering the temperature, these bodies are to a certain extent rejected, and nearly, but not quite, pure ice is formed; and so far as we know this equally applies to fused iron. As an instance, on cooling, the carbon is rejected, and appears in the graphitic $^{1}$ form, merely diffused throughout the solid cold metal. It is impossible here to treat this matter in detail ; but enough, we think, has been said to indicate that the analogy is fairly complete throughout.

But there is another matter-apart from the solution of foreign bodies in fused ice or iron-which requires to be discussed. Ice dissolves in warm water, and so does cold iron or steel in superheated fused iron; the hot fluid metal from the Bessemer converter fuses or dissolves large lumps of solid steel placed in it as easily as ice is thawed in warm water. Temperature here, in both instances, determines the quantity which can be added; the higher the heat, the greater the quantity which can thus be dissolved or fused, ere the bath becomes thick, pasty, and incapable of being poured out into another vessel.

In so-called solutions the same rule appears to hold good ; but, as all chemists know, there are many exceptions ; in some cases heat is evolved, in others absorbed; and some bodies are more soluble in the cold fluid solvent.

It is, however, believed that no instance can be quoted of a body being more soluble in iron at a low degree of heat than at a high one. Confining ourselves to hot fluid iron or steel, it apparently readily dissolves cold metal. Similarly, other bodies, such as copper, \&c., are dissolved in the same way when added to it.

The cold metal is fused by absorption of the enormous

t The relations existing betwixt carbon and iron are peculiar, and require to be separately discussed. 